\title{
Trends in cigarette consumption cannot fully explain trends in British lung cancer rates
}

\author{
Peter N Lee, Barbara A Forey
}

\begin{abstract}
Study objectives-To determine whether British lung cancer (LC) trends are adequately explained by cigarette smoking trends, and whether modelling using aggregated smoking prevalence estimates can validly replace modelling using individual smoking histories.
\end{abstract}

Methods-Observed LC trends for 19551985 for both sexes and three age groups were compared with multistage model predictions using smoking history data from two surveys (HALS, AHIP). The modelling used the individual smoking data directly or aggregated prevalence estimates. It allowed for variation in age of starting and stopping smoking, amount smoked, tar levels, and environmental tobacco smoke (ETS) exposure.

Results-Observed male LC rates fell faster than predicted by a model (with the first and penultimate stages assumed affected by smoking) that allowed for variation in amount smoked and in tar level (with some provision for "compensation"), and was based on aggregated smoking data from HALS. The discrepancy equated to an annual change unexplained by smoking of $-2.4 \%,-2.8 \%$, and $-1.9 \%$ for ages $35-44,45-54$, and $55-64$. The annual unexplained changes were less in women, and reversed at age 55-64; $-1.7 \%,-0.8 \%$, and $+0.8 \%$ for the three ages. They were similar using individual smoking histories $(-2.6 \%,-1.8 \%$, and $-1.6 \%$; women, $-0.9 \%,-0.5 \%$, and $+0.2 \%$ ). The discrepancies were unexplained by plausible alternative multistage parameters, full allowance for tar reduction, alternative estimates of amount smoked, or ETS.

Conclusions-British LC trends cannot be fully explained by cigarette consumption trends, implying factors other than cigarette smoking contribute importantly to overall risk. Predictions using aggregated prevalence estimates provide useful information.

(F Epidemiol Community Health 1998;52:82-92)

P N Lee Statistics and Computing Ltd, 17 Cedar Road, Sutton, Surrey, SM2 5DA, UK

Correspondence to: Mr Lee.

Accepted for publication 26 August 1997
Peto et $a l^{1}$ estimated over $90 \%$ of male lung cancer (LC) deaths in developed countries were attributable to smoking. There are, however, many other LC risk factors, including occupational, dietary, psychological and familial factors, previous lung disease, exposures to chemicals, and air pollution. ${ }^{2} 3$ How much mortality arises from these factors is uncertain.
We compare observed British LC trends for 1955-85 with trends predicted based only on smoking, using smoking history data for people from the 1984-85 Health and Lifestyle Study $(\text { HALS })^{4}$ and patients with diseases "probably or definitely not associated with smoking" from the Alderson Hospital In-Patients Study (AHIP). ${ }^{5}$ Elsewhere we show recalled data from these studies permit estimation of sex and cohort specific trends in smoking prevalence accurately mirroring trends evident in surveys conducted since 1948 for the Tobacco Manufacturers Association (TMA) (submitted for publication). We predict risk using a multistage carcinogenesis model $^{6}$ allowing for people to start and stop smoking at different times and to vary their "dose" from cigarettes (from changes in amount smoked or tar level).

Other studies predicting LC trends ${ }^{7-9}$ have not used individual smoking history data, but aggregated data in the form of age and sex specific smoking prevalence estimates at different times. We also apply the model to aggregated data derived from HALS and AHIP, to assess the usefulness of this method.

\section{Methods}

DEATH RATES AND POPULATIONS

Population and mortality data for England and Wales (EW), and Scotland, by sex and age (35-39, 40-44 ..., 60-64) were obtained from $\mathrm{WHO}^{10}$ for $1955,1956 \ldots$ 1985. Populations for single years of age were estimated by dividing five year age group data by five. Observed rates are presented by 10 year ages $(35-44 \ldots$. 55-64) adjusted to the single year age distribution of the sex specific EW population in 1970 . Observed rates for age 35-44 are smoothed using five year averages. Although diagnosis of LC is inaccurate, ${ }^{11}$ no misdiagnosis adjustment has been made as no meaningful improvements in detection of LC have occurred since $1955 .^{12}$

MULTISTAGE CARCINOGENESIS MODELS

The multistage model was introduced ${ }^{6}$ to explain cancer death rates often rising as an approximate power of age. ${ }^{13}{ }^{14}$ It assumes a cell only generates a cancer after undergoing a number of heritable changes. For each person, the relevant tissue initially contains $\mathrm{N}$ normal cells, each equally likely to progress to cancer. The progression occurs in a specific order, the background rate for each change being constant. Carcinogens increase transition rate(s) above background.

We used the multistage model based on a detailed review, ${ }^{15}$ concluding predictions based on it should be reliable. The model is flexible and tractable. Its predictions fit in reasonably 
Table 1 Values of $d_{1}$ and $d_{2}$ used to define multistage models with chosen values of ratio of first to penultimate stage effects $\left(d_{1}: d_{2}\right)$ and smoking risk $(R)^{\star}$

\begin{tabular}{|c|c|c|c|c|c|c|}
\hline \multirow[b]{2}{*}{$d_{1}: d_{2}$} & \multicolumn{2}{|c|}{$R=10$} & \multicolumn{2}{|c|}{$R=20$} & \multicolumn{2}{|l|}{$R=40$} \\
\hline & $d_{1}$ & $d_{2}$ & $d_{1}$ & $d_{2}$ & $d_{1}$ & $d_{2}$ \\
\hline $1: 0$ & 32.85 & 0.00 & 69.34 & 0.00 & 142.33 & 0.00 \\
\hline $5: 1$ & 9.20 & 1.84 & 14.79 & 2.96 & 22.70 & 4.54 \\
\hline $2: 1$ & 5.76 & 2.88 & 9.29 & 4.64 & 14.29 & 7.14 \\
\hline $1: 1$ & 3.86 & 3.86 & 6.32 & 6.32 & 9.83 & 9.83 \\
\hline $1: 2$ & 2.48 & 4.96 & 4.17 & 8.34 & 6.62 & 13.23 \\
\hline $1: 5$ & 1.28 & 6.41 & 2.27 & 11.35 & 3.75 & 18.75 \\
\hline $0: 1$ & 0.00 & 9.02 & 0.00 & 19.04 & 0.00 & 39.08 \\
\hline
\end{tabular}

${ }^{\star} \mathrm{R}$ is the risk for a smoker smoking a standard "dose" from cigarettes for three quarters of his life relative to that of a never smoker; $\mathrm{K}-1=4.5$ has been assumed.

well with the approximate power law relation of incidence with duration of exposure to a strong carcinogen, ${ }^{141617}$ the lack of relation of incidence with age, given duration, for some carcinogens, ${ }^{17-19}$ initiation/promotion studies showing cancer requires multiple exposures in a specific order ${ }^{2021}$ increases in incidence from an exposure long ceased, ${ }^{1622} 23$ evidence of a quadratic dose response for some carcinogens, ${ }^{24} 25$ and the joint effect of two carcinogens often being multiplicative or super additive. ${ }^{26}$ Some suggest ${ }^{27}{ }^{28}$ the model inadequately describes risk after quitting smoking but this was based on limited data, ${ }^{15}$ larger data sets $^{23}{ }^{29}$ showing patterns consistent with multistage predictions ${ }^{15}{ }^{30}$ and conflicting with another model proposed. ${ }^{28}$

Our review, ${ }^{15}$ based partly on other work,,$^{30-33}$ fully describes how incidence depends on age, dose, duration and cessation of exposure, and the number of stages affected.

For a non-smoker risk at age $\mathrm{T}$ is approximated by:

$$
\mathrm{R}_{\mathrm{n}}(\mathrm{T})=\mathrm{aT} \mathrm{T}^{\mathrm{K}-1}
$$

$\mathrm{a}$ is a constant and $\mathrm{K}$ the number of stages.

For a smoker starting at age $S$ and smoking for duration $\mathrm{D}(=\mathrm{T}-\mathrm{S})$ risk increases, depending on the stages affected by smoking. Following previous work ${ }^{152-34}$ attention was restricted to models with only the first and penultimate stages affected. Risk at age $\mathrm{T}$ is approximated by:

$$
\begin{aligned}
& \mathrm{R}_{\mathrm{c}}(\mathrm{T})= \\
& \mathrm{a}\left(\mathrm{T}^{\mathrm{K}-1}+\mathrm{d}_{1} \mathrm{D}^{\mathrm{K}-1}+\mathrm{d}_{2}\left(\mathrm{~T}^{\mathrm{K}-1}-\mathrm{S}^{\mathrm{K}-1}\right)+\mathrm{d}_{1} \mathrm{~d}_{2} \mathrm{D}^{\mathrm{K}-1}\right)
\end{aligned}
$$

$\mathrm{d}_{1}$ and $\mathrm{d}_{2}$ are excess effects relative to background for the first and penultimate stages - that is, $d=4$ implies smoking multiplies the background probability by 5 .

Table 2 Estimates of cigarettes smoked per smoker ${ }^{*}$, based on TMA surveys since 1950, and on alternative guesstimates at earlier years

\begin{tabular}{llllll}
\hline & \multicolumn{3}{l}{ Men } & & \multicolumn{2}{l}{ Women } \\
\cline { 2 - 3 } \cline { 5 - 5 } Yeart & $G B(1)$ & $G B(2)$ & & $G B(1)$ & $G B(2)$ \\
\hline 1890 & 10 & 1 & & 5 & 1 \\
1905 & 10 & 4 & & 5 & 1 \\
1935 & 10 & 10 & & 5 & 5 \\
1950 & & 15 & & 10 \\
1955 & & 18 & & 11 \\
1960 & & 19 & & 12 \\
1965 & & 19 & & 14 \\
1970 & & 20 & & 16 \\
1975 & & 22 & & 16 \\
1980 & & 21 & &
\end{tabular}

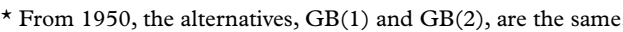
+ Data for intermediate years estimated by linear interpolation.
Table 3 Sales weighted average tar yield (SWAT) of UK cigarettes ( $\mathrm{mg} / \mathrm{cig})$, according to two different sources

\begin{tabular}{lll}
\hline Year & TMA SWAT & Wald SWAT \\
\hline 1937 & & 32.9 \\
1944 & & 32.2 \\
1951 & & 29.5 \\
1958 & 31.5 & 30.4 \\
1965 & 30.3 & 26.0 \\
1966 & 26.0 & \\
1967 & 23.9 & \\
1968 & 23.9 & \\
1969 & 22.5 & 25.7 \\
1970 & 21.3 & 23.6 \\
1971 & 20.5 & 21.0 \\
1972 & 18.7 & 19.9 \\
1973 & 18.1 & 19.3 \\
1974 & 17.9 & 18.8 \\
1975 & 17.8 & 17.9 \\
1976 & 17.4 & 17.6 \\
1977 & 17.4 & 17.5 \\
1978 & 16.8 & 16.8 \\
1979 & 16.3 & 16.4 \\
1980 & 15.8 & 15.9 \\
1981 & 15.4 & 15.4 \\
1982 & 15.0 & 15.1 \\
1983 & 14.6 & 14.8 \\
1984 & 14.4 & 14.4 \\
1985 & & \\
\hline
\end{tabular}

We allowed for various values of $d_{1}: d_{2}$ and of the strength $(R)$ of the association of smoking with LC. $\mathrm{R}$ is defined as the risk, relative to a non-smoker, of a smoker who, for three quarters of his life, smokes a standard "dose" (vide infra). Table 1 shows the $d_{1}: d_{2}$ and $R$ values we used and the corresponding $d_{1}$ and $d_{2}$ values for $K-1=4.5$. The seven $d_{1}: d_{2}$ values are not equally plausible. $d_{1}: d_{2}=1: 0$ cannot explain the declining risk on smoking cessation, while $\mathrm{d}_{1}: \mathrm{d}_{2}=0: 1$ cannot explain the strong relation of risk to age of starting given age. Model fitting work we reviewed ${ }^{15}$ suggests $d_{1} \simeq d_{2}$, Brown and $\mathrm{Chu}^{30}$ presenting analyses suggesting best fit for $\mathrm{d}_{1}: \mathrm{d}_{2}=1: 2$.

Elsewhere, $\mathrm{we}^{15}$ extended the above formula to allow for quitting smoking, and more generally for intermediate periods of cessation. Here, we further allow for changing number smoked or tar level. For someone living in $\mathrm{T}$ equal annual periods $(i=1, . . \mathrm{T})$ during which the "dose" from cigarettes is $Z_{\mathrm{i}}$, risk at time $\mathrm{T}$ is approximated by:

$$
\begin{aligned}
& \mathrm{R}_{\mathrm{v}}(\mathrm{T})= \\
& \mathrm{a}\left(\mathrm{T}^{\mathrm{K}-1}+\mathrm{d}_{1} \sum_{\mathrm{i}=1}^{\mathrm{T}} \mathrm{F}_{\mathrm{i}} \mathrm{Z}_{\mathrm{i}}+\mathrm{d}_{2} \sum_{\mathrm{i}=1}^{\mathrm{T}} \mathrm{G}_{\mathrm{i}} \mathrm{Z}_{\mathrm{i}}+\mathrm{d}_{1} \mathrm{~d}_{2} \sum_{\mathrm{i}=1}^{\mathrm{T}} \sum_{\mathrm{j}=1}^{\mathrm{T}} \mathrm{H}_{\mathrm{ij}} \mathrm{Z}_{\mathrm{i}} \mathrm{Z}_{\mathrm{i}}\right) \\
& \text { where } \mathrm{F}_{\mathrm{i}}=(\mathrm{T}-\mathrm{i}+1)^{\mathrm{K}-1}-(\mathrm{T}-\mathrm{i})^{\mathrm{K}-1} \\
& \mathrm{G}_{\mathrm{i}}=\mathrm{F}_{\mathrm{T}-\mathrm{i}+1} \text { and } \\
& \mathrm{H}_{\mathrm{ij}}=1 \text { if } \mathrm{i}=\mathrm{j}, \text { or } \\
& \mathrm{H}_{\mathrm{ij}}=(\mathrm{j}-\mathrm{i}+1)^{\mathrm{K}-1}-2(\mathrm{j}-\mathrm{i})^{\mathrm{K}-1}+(\mathrm{j}-\mathrm{i}-1)^{\mathrm{K}-1} \text { if } \mathrm{i}<\mathrm{j}
\end{aligned}
$$

The formula predicts risk using smoking data every year up to age T. We also allowed a "lag time" between LC onset and mortality, so smoking to age $\mathrm{T}$ would predict mortality at age $\mathrm{T}+\mathrm{L}$. In many analyses "standard multistage parameter values" of $\mathrm{d}_{1}: \mathrm{d}_{2}=1: 2, \mathrm{R}=20$, $\mathrm{L}=5$ and $\mathrm{K}-1=4.5$ are used. Alternative values (see tables 1 and 6 ) are sometimes used in analyses.

SMOKING DATA

HALS and AHIP are described fully elsewhere (submitted data). ${ }^{45}$ Here only the regular cigarette smoking data are used. HALS, but not 
Table 4 Average tar level at two time points by sex and birth cohort (AHIP study)

\begin{tabular}{|c|c|c|c|c|c|}
\hline \multirow[b]{2}{*}{ Sex } & \multirow[b]{2}{*}{ Birth cohort } & \multicolumn{2}{|c|}{ Current ${ }^{\star}$} & \multicolumn{2}{|c|}{10 years ago * } \\
\hline & & $N \dagger$ & Tar level (mg/cig) & $N t$ & Tar level ( $\mathrm{mg} / \mathrm{cig})$ \\
\hline \multirow[t]{5}{*}{ Men } & 1900-09 & 46 & 16.6 & 103 & 28.6 \\
\hline & 1910-19 & 197 & 17.4 & 364 & 27.6 \\
\hline & $1920-29$ & 276 & 17.0 & 445 & 28.6 \\
\hline & $1930-39$ & 212 & 17.7 & 313 & 29.1 \\
\hline & $1940-49$ & 69 & 17.4 & 102 & 28.6 \\
\hline \multirow[t]{5}{*}{ Women } & 1900-09 & 32 & 15.3 & 60 & 28.1 \\
\hline & 1910-19 & 151 & 16.0 & 283 & 27.9 \\
\hline & $1920-29$ & 261 & 15.6 & 359 & 26.3 \\
\hline & 1930-39 & 125 & 15.5 & 157 & 25.0 \\
\hline & $1940-49$ & 26 & 15.1 & 32 & 22.3 \\
\hline
\end{tabular}

$\star$ Relative to year of hospital admission. $\dagger$ Number of smokers of manufactured cigarettes for whom tar delivery of usual brand was available.

AHIP, included handrolled cigarettes. In both studies ages of starting and stopping were available. HALS recorded current or usual amount smoked, while AHIP recorded amount smoked at intervals from age 16 and brand smoked in the 10 years before admission.

Aggregated estimates, by sex, cohort, and year, of cigarette smoking prevalence in HALS and AHIP and of consumption per smoker in AHIP were calculated as previously (submitted data).

Simpler consumption estimates, by sex and year, were also used (table 2). From 1950 data came from TMA. Earlier data were "guesstimates". Between the 1930s and 1950s we assumed consumption/smoker approximately doubled, using limited evidence from $\mathrm{USA}^{35}$ and Norway ${ }^{36}$ (consistent with the rise in UK sales $^{37}$ ) and from AHIP. Before 1935, we assumed consumption was either constant before 1935 (GB(1) estimate) or rising from 1/day in 1890 for men and 1905 for women (GB(2) estimate).

Data $^{37}$ from TMA and Wald on sales weighted average tar (SWAT) delivery of UK cigarettes are shown in table 3. Both sources give SWAT falling from about 32 to 13 $\mathrm{mg} /$ cigarette. TMA saw no reason to believe levels fell much before $1965,{ }^{38}$ but Wald claims earlier falls. Data for early years are assumed equal to the first value given, intermediate values being estimated by interpolation.

Individual smoking histories

Smoking histories were estimated for HALS and AHIP. For HALS, subjects were assumed to have smoked continuously from age of starting to interview or age of stopping. For AHIP, for each year between age of starting and hospital admission or stopping, cigarette consumption was estimated from the nearest available data on number smoked.

Table 4 shows tar level from AHIP for two time points. Current level was available for $93 \%$ of current smokers, being slightly lower for women than men, not varying with age, and similar to SWAT for the same period. For smokers 10 years ago, tar was available for $90 \%$ of men and $85 \%$ of women. For women, it increased with age. Levels were somewhat higher than SWAT.

When tar was unavailable from AHIP, it was estimated by multiplying SWAT by the ratio of AHIP tar to SWAT for the nearest available time point.

\section{"Dose" to a smoker}

"Dose" to a smoker in year $\mathrm{i}, \mathrm{Z}_{\mathrm{i}}$, was defined relative to a standard smoker of $20 \mathrm{cig} /$ day of $31.5 \mathrm{mg} / \mathrm{cig}$ tar. In analyses considering cigarette consumption, "dose" was estimated by dividing consumption by 20 . In analyses considering tar, "dose" was multiplied by either $\operatorname{tar} / 31.5$ or $\sqrt{\operatorname{tar} / 31.5}$, the latter attempting allowance for "compensation" for reduced yield by increased inhalation or puff number. ${ }^{39} 40$

Table 5 Fifteen year percentage changes (by sex, age, and period) in the lung cancer rate observed and in that predicted from the HALS study using the aggregate method, and different methods of estimating "dose" from cigarettes

\begin{tabular}{|c|c|c|c|c|c|c|c|c|c|c|c|c|c|c|}
\hline & & & \multicolumn{6}{|l|}{ Men } & \multicolumn{6}{|l|}{ Women } \\
\hline & & & \multicolumn{2}{|l|}{$35-44$} & \multicolumn{2}{|l|}{$45-54$} & \multicolumn{2}{|l|}{$55-64$} & \multicolumn{2}{|l|}{$35-44$} & \multicolumn{2}{|l|}{$45-54$} & \multicolumn{2}{|l|}{$55-64$} \\
\hline & & & $\begin{array}{l}1955- \\
1970\end{array}$ & $\begin{array}{l}1970- \\
1985\end{array}$ & $\begin{array}{l}1958- \\
1970^{\star}\end{array}$ & $\begin{array}{l}1970- \\
1985\end{array}$ & $\begin{array}{l}1955- \\
1970\end{array}$ & $\begin{array}{l}1970- \\
1985\end{array}$ & $\begin{array}{l}1955- \\
1970\end{array}$ & $\begin{array}{l}1970- \\
1985\end{array}$ & $\begin{array}{l}1955- \\
1970\end{array}$ & $\begin{array}{l}1970- \\
1985\end{array}$ & $\begin{array}{l}1958- \\
1970^{\star}\end{array}$ & $\begin{array}{l}1970- \\
1985\end{array}$ \\
\hline \multicolumn{3}{|l|}{ Country } & \multicolumn{12}{|c|}{ Observed changes (\%) } \\
\hline \multirow{2}{*}{\multicolumn{3}{|c|}{$\begin{array}{l}\text { Britain } \\
\text { England and Wales }\end{array}$}} & -21.3 & -44.3 & -12.4 & -37.6 & 13.9 & -21.9 & 36.5 & -23.7 & 91.6 & -12.9 & 77.0 & 66.6 \\
\hline & & & -22.4 & -45.0 & -13.8 & -39.1 & 13.4 & -23.0 & 35.1 & -24.1 & 89.0 & -12.7 & 75.4 & 64.2 \\
\hline \multicolumn{15}{|l|}{ Dose assumptions } \\
\hline Cig per smoker & $\begin{array}{l}\text { Tarper } \\
\text { cigarette }\end{array}$ & $\begin{array}{l}E T S \\
(F)\end{array}$ & \multicolumn{6}{|c|}{ Predicted changes (\%) $\dagger$} & & & & & & \\
\hline Constant‡ & Constant & 0.00 & -6.3 & -13.7 & 0.5 & -19.1 & & -7.7 & 32.0 & -5.7 & 64.3 & 0.6 & 36.2 & 49.7 \\
\hline $\mathrm{GB}(1)$ & Constant & 0.00 & 29.3 & 1.4 & 28.8 & 1.5 & & 16.4 & 60.1 & 26.4 & 76.7 & 36.4 & 45.4 & 79.0 \\
\hline $\mathrm{GB}(1)$ & TMA-sqrt & 0.00 & 29.3 & -16.7 & 28.8 & -14.2 & & 0.7 & 60.1 & 5.9 & 76.7 & 16.6 & 45.4 & 55.4 \\
\hline $\mathrm{GB}(1)$ & TMA-full & 0.00 & 29.3 & -30.5 & 28.8 & -26.3 & & -11.3 & 60.1 & -9.6 & 76.7 & 1.5 & 45.4 & 37.2 \\
\hline $\mathrm{GB}(2)$ & Constant & 0.00 & 30.3 & 1.4 & 32.4 & 1.6 & & 18.8 & 60.4 & 26.4 & 78.8 & 36.5 & 48.2 & 80.2 \\
\hline $\mathrm{GB}(2)$ & TMA-sqrt & $0.00 \$$ & 30.3 & -16.7 & 32.4 & -14.2 & & 2.9 & 60.4 & 5.9 & 78.8 & 16.7 & 48.2 & 56.4 \\
\hline $\mathrm{GB}(2)$ & TMA-full & 0.00 & 30.3 & -30.5 & 32.4 & -26.2 & & -9.5 & 60.4 & -9.6 & 78.8 & 1.5 & 48.2 & 38.2 \\
\hline $\mathrm{GB}(2)$ & Wald-sqrt & 0.00 & 24.8 & -13.5 & 28.6 & -12.1 & & 4.6 & 55.2 & 9.5 & 73.6 & 19.5 & 45.4 & 59.1 \\
\hline $\mathrm{GB}(2)$ & Wald-full & 0.00 & 19.6 & -25.2 & 25.0 & -23.0 & & -6.7 & 50.2 & -3.5 & 68.8 & 6.2 & 42.7 & 42.4 \\
\hline AHIP & Constant & 0.00 & 8.2 & -4.1 & 15.5 & -8.3 & & 9.6 & 38.0 & 16.5 & 69.6 & 22.0 & 44.0 & 60.9 \\
\hline AHIP & TMA-sqrt & 0.00 & 8.2 & -21.8 & 15.5 & -23.0 & & -5.5 & 38.0 & -3.0 & 69.6 & 4.1 & 44.0 & 40.0 \\
\hline AHIP & TMA-full & 0.00 & 8.2 & -35.2 & 15.5 & -34.3 & & -17.1 & 38.0 & -17.7 & 69.6 & -9.6 & 44.0 & 23.9 \\
\hline $\mathrm{GB}(2)$ & TMA-sqrt & 0.05 & 32.2 & -14.7 & 33.6 & -12.2 & & 4.5 & 61.1 & 8.0 & 78.3 & 18.7 & 48.3 & 56.7 \\
\hline $\mathrm{GB}(2)$ & TMA-sqrt & 0.20 & 37.4 & -9.3 & 36.9 & -6.7 & & 9.2 & 63.3 & 13.5 & 78.0 & 24.2 & 49.5 & 57.7 \\
\hline
\end{tabular}

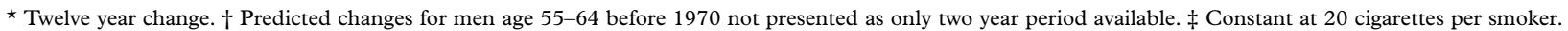
$\int$ “Standard" model. All predictions use a multistage model with $\mathrm{d}_{1}: \mathrm{d}_{2}=1: 2, \mathrm{R}=20, \mathrm{~K}-1=4.5, \mathrm{~L}=5$, and the Swartz smoking submodel with $\mathrm{S}$ ' $=15$. 


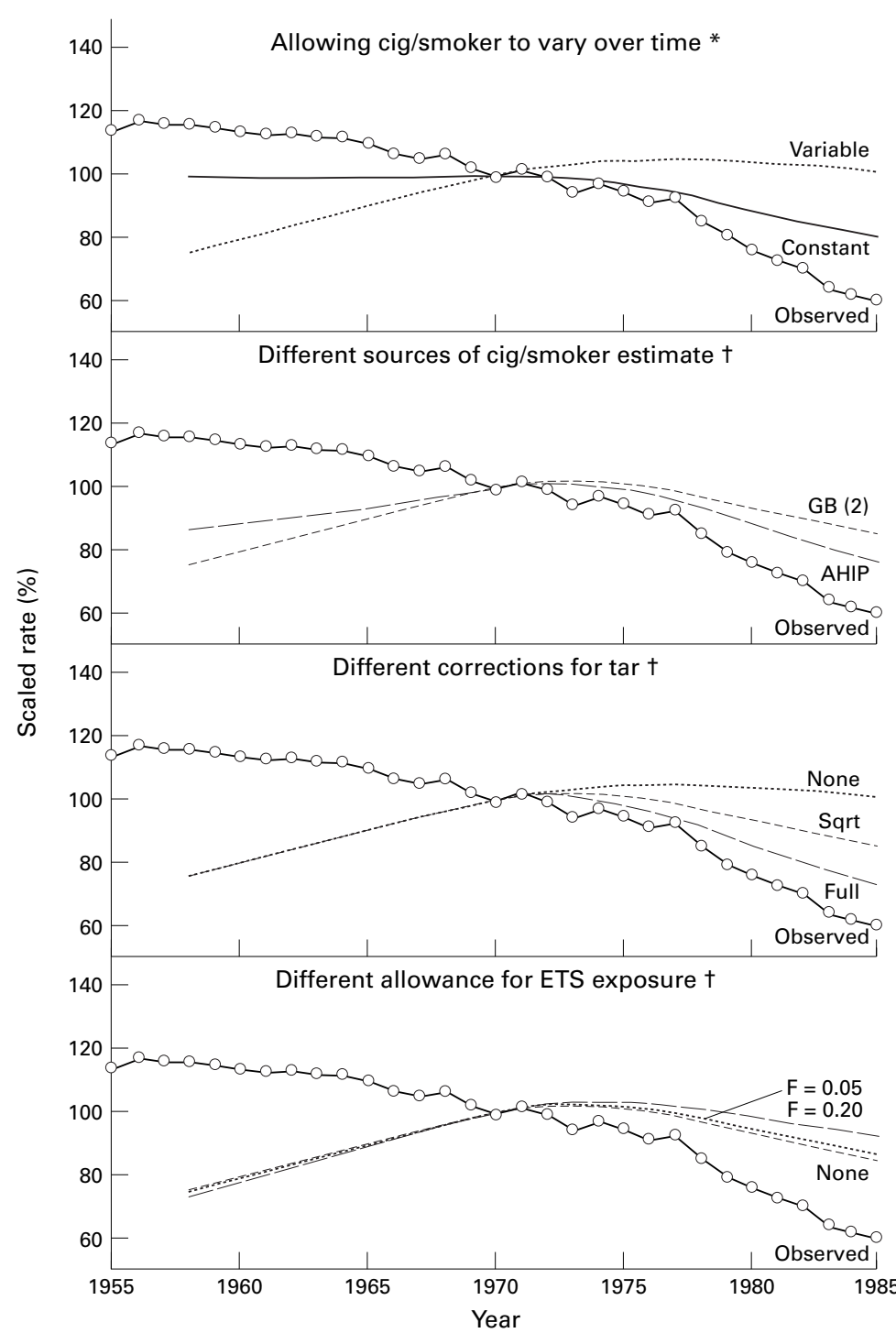

Figure 1 Comparison of observed lung cancer trends in EW for men aged 45-54 and those predicted from the HALS study using the aggregate method and different methods of estimating "dose". ${ }^{\star}$ Constant $=20$ cigarettes per smoker per day, no tar correction, no dose from ETS; variable $=G B(2)$ estimate of cigarettes per smoker, no tar correction, no dose from ETS. + Except where shown otherwise, predictions use $G B(2)$ estimate of cigarettes per smoker, TMA estimates of tar per cigarette with square root correction and no dose from ETS. All predictions use a multistage model with $d_{1}: d_{2}=1: 2, R=20, K-1=4.5, L=5$, and the Swartz smoking submodel with $S^{\prime}=15$.

Environmental tobacco smoke (ETS) exposure

To allow for ETS exposure, $\pi_{\mathrm{i}}$, the dose from ETS, was added to $Z_{\mathrm{i}}$, the dose from smoking. $\pi_{\mathrm{i}}$ was estimated by $\mathrm{C}_{\mathrm{i}} \mathrm{F}$, with $\mathrm{C}_{\mathrm{i}}$ the average number smoked per adult in the population estimated from sales data ${ }^{37}$ and $\mathrm{F}$ a factor representing $\alpha$, the average number of adults a subject is exposed to, multiplied by $\beta$, the strength of a cigarette smoked passively relative to one smoked actively. $\alpha$ and $\beta$ cannot be estimated, but F can be. Based on cotinine, ETS exposed non-smokers have a nicotine intake no more than 0.2 cigarettes per day. ${ }^{3}$ For $C_{i}=10$ (about the maximum UK level), this implies $\mathrm{F}$ is no more than 0.02 . We used higher $F$ values, 0.05 and 0.2 , because values below 0.05 hardly affected predictions and because relative exposure from passive and active smoking is higher for some vapour phase constituents. ${ }^{41}$ Even so,
$\mathrm{F}=0.2$ is implausibly high, estimates using it being included only to show effects of ETS on predictions were minimal.

\section{RISK PREDICTION}

Individual method

For each subject risk was estimated for each age from 35 to 64 , using smoking history up to L years before, taking account of age of starting and stopping and, according to the model, the variable "dose" from cigarettes. For $\mathrm{L}=0$, estimates were calculated to 1985 (HALS) or year of admission (AHIP).

For both sexes, each year from 1955 to 1985 and each age from 35 to 64, predictions were averaged from all relevant subjects, if $\geqslant 10$. Rates for ages 35-44, 45-54, and 55-64 were then calculated for years where the full 10 year age range was present, age adjusted to the 1970 EW population. Thus subjects born in 1900 contributed to the 55-64 rate as 55 year olds in 1955, 56 year olds in 1956, etc, until they exceeded the age limit in 1965. As, for both sexes in AHIP, the earliest cohort with $10+$ subjects was born in 1904, predictions are only available from 1958 and 1968 for ages 45-54 and 55-64 respectively. In HALS, the earliest cohorts with $10+$ subjects were born in 1901 (men) and 1898 (women), so predictions started earlier. For AHIP, reducing numbers of subjects in each cohort after hospital admissions started made predictions less reliable for the final few years.

\section{Aggregate method}

As described by Swartz, ${ }^{7}$ cohort based smoking prevalence estimates and a smoking "submodel" were used to generate estimates of proportions starting and stopping smoking at each combination of ages. For each subgroup LC risks were then calculated as in the individual method. The predicted age adjusted rate for the whole population was also calculated equivalently, but weighting each subgroup according to size. Following Swartz, we assumed 10 year birth cohort prevalence data applied to the mid-year, interpolating prevalences for cohorts born in intermediate years.

Three smoking submodels were used: (1) "Swartz"7 assumes that, whenever prevalence in a cohort increases, the appropriate number of never smokers become smokers, and whenever it decreases, an equal proportion of each age of starting subgroup of current smokers become ex-smokers (subjects cannot stop then restart. The probability of quitting is independent of age of starting); (2) "Swartz with drift" 7 assumes additional never smoking subjects, equal to $0.5 \%$ of current smokers, start smoking each year, an identical number of current smokers becoming ex-smokers; (3) "Townsend" assumes subjects are ranked by "desire to smoke". When prevalence increases, ex-smokers smoking previously for the longest time are assumed to restart, never smokers becoming smokers only if no exsmokers are available. When prevalence decreases, most recent starters are assumed to become ex-smokers. 
Table 6 Fifteen year percentage changes (by sex, age, and period) in the lung cancer rate observed and in that predicted from the HALS study using the aggregate method, and differing multistage model parameters and smoking submodels

\begin{tabular}{|c|c|c|c|c|c|c|c|c|c|c|c|c|}
\hline & \multicolumn{6}{|l|}{ Men } & \multicolumn{6}{|l|}{ Women } \\
\hline & \multicolumn{2}{|l|}{$35-44$} & \multicolumn{2}{|l|}{$45-54$} & \multicolumn{2}{|l|}{$55-64$} & \multicolumn{2}{|l|}{$35-44$} & \multicolumn{2}{|l|}{$45-54$} & \multicolumn{2}{|l|}{$55-64$} \\
\hline & $\begin{array}{l}1955- \\
1970\end{array}$ & $\begin{array}{l}1970- \\
1985\end{array}$ & $\begin{array}{l}1958- \\
1970^{\star}\end{array}$ & $\begin{array}{l}1970- \\
1985\end{array}$ & $\begin{array}{l}1955- \\
1970\end{array}$ & $\begin{array}{l}1970- \\
1985\end{array}$ & $\begin{array}{l}1955- \\
1970\end{array}$ & $\begin{array}{l}1970- \\
1985\end{array}$ & $\begin{array}{l}1955- \\
1970\end{array}$ & $\begin{array}{l}1970- \\
1985\end{array}$ & $\begin{array}{l}1958- \\
1970^{\star}\end{array}$ & $\begin{array}{l}1970- \\
1985\end{array}$ \\
\hline Country & \multicolumn{12}{|c|}{ Observed changes (\%) } \\
\hline England and Wales & -22.4 & -45.0 & -13.8 & -39.1 & 13.4 & -23.0 & 35.1 & -24.1 & 89.0 & -12.7 & 75.4 & 64.2 \\
\hline Model assumptions & \multicolumn{12}{|c|}{ Predicted changes $(\%) \dagger$} \\
\hline Standard & 30.3 & -16.7 & 32.4 & -14.2 & & 2.9 & 60.4 & 5.9 & 78.8 & 16.7 & 48.2 & 56.4 \\
\hline$\underset{1: 0}{\text { Varying } \mathrm{d}_{1}: \mathrm{d}_{2}}$ & & & & & & & & & & & & \\
\hline $1: 0$ & 26.5 & 15.1 & 33.7 & 19.2 & & 43.3 & 34.1 & 20.9 & 61.4 & 36.3 & 35.9 & 92.3 \\
\hline $5: 1$ & 34.4 & -8.8 & 38.9 & -3.5 & & 17.2 & 44.2 & 10.4 & 61.8 & 23.4 & 36.8 & 65.6 \\
\hline $2: 1$ & 33.0 & -12.5 & 36.6 & -8.1 & & 11.2 & 50.4 & 8.3 & 67.7 & 20.5 & 40.6 & 61.3 \\
\hline $1: 1$ & 31.6 & -14.9 & 34.6 & -11.3 & & 6.8 & 55.5 & 7.0 & 73.1 & 18.4 & 44.3 & 58.6 \\
\hline $1: 5$ & 28.7 & -18.6 & 29.9 & -17.2 & & -1.6 & 66.1 & 4.8 & 85.7 & 14.8 & 52.9 & 54.2 \\
\hline $0: 1$ & 26.4 & -21.1 & 25.9 & -21.7 & & -8.6 & 75.3 & 3.2 & 97.7 & 12.1 & 61.3 & 51.1 \\
\hline \multicolumn{13}{|l|}{ Varying $\mathrm{R}$} \\
\hline 10 & 24.5 & -15.7 & 26.1 & -14.2 & & 0.2 & 43.4 & 4.0 & 53.9 & 11.9 & 32.6 & 40.0 \\
\hline 40 & 36.0 & -16.9 & 38.7 & -13.1 & & 6.2 & 77.7 & 8.2 & 106.4 & 22.0 & 65.3 & 74.2 \\
\hline \multicolumn{13}{|l|}{ Varying $\mathrm{K}-1$} \\
\hline 3 & 37.0 & -11.9 & 38.7 & -7.5 & & 12.7 & 60.0 & 11.8 & 80.5 & 22.6 & 47.7 & 64.6 \\
\hline 6 & 26.6 & -21.1 & 27.9 & -19.6 & & -5.0 & 62.7 & 1.5 & 79.0 & 12.4 & 49.3 & 50.4 \\
\hline \multicolumn{13}{|l|}{ Varying L } \\
\hline 0 & 18.2 & -23.9 & 20.2 & -19.7 & & -5.0 & 54.6 & -3.5 & 76.0 & 8.8 & 44.3 & 48.8 \\
\hline 10 & 35.3 & -6.8 & 36.4 & -5.9 & & 13.3 & 59.7 & 14.9 & 76.1 & 24.1 & 46.8 & 63.4 \\
\hline \multicolumn{13}{|l|}{$\begin{array}{l}\text { Varying smoking } \\
\text { submodel }\end{array}$} \\
\hline Swartz with drift & 29.9 & -16.8 & 31.7 & -14.4 & & 2.3 & 60.1 & 5.7 & 77.9 & 16.2 & 47.5 & 54.9 \\
\hline Townsend & 30.5 & -15.6 & 33.2 & -13.3 & & 3.3 & 60.5 & 6.5 & 79.3 & 17.3 & 48.7 & 57.5 \\
\hline \multicolumn{13}{|l|}{ Varying S' } \\
\hline 12 & 31.4 & -15.2 & 33.9 & -13.5 & & 3.7 & 61.7 & 6.5 & 79.7 & 17.3 & 48.4 & 57.5 \\
\hline 21 & 25.4 & -20.7 & 27.6 & -17.5 & & -1.5 & 55.2 & 2.0 & 72.8 & 13.5 & 46.2 & 50.3 \\
\hline
\end{tabular}

* Twelve year change. $†$ Predicted changes for men age 55-64 before 1970 not presented as only two year period available. All predictions use GB(2) estimates of cigarettes per smoker, TMA estimates of tar per cigarette with square root correction and no dose from ETS. The standard multistage model uses $\mathrm{d}_{1}: \mathrm{d}_{2}=1: 2, \mathrm{R}=20$, $\mathrm{K}-1=4.5, \mathrm{~L}=5$, and the Swartz smoking submodel with $S^{\prime}=15$. Other models shown vary one parameter at a time.

The different ways the submodels treat prevalence increases made little difference, as most increases occurred together at the younger ages, relatively few smokers restarting under "Townsend". The treatment of prevalence decreases had more effect, with the Swartz submodels, especially with drift, minimising, and "Townsend" maximising, long term smoking.

For each submodel, a minimum age when smoking can start, $S^{\prime}$, was set. Although $S^{\prime}=0$ could be used, so fully accounting for the age of starting pattern in each cohort, prevalence estimates among children were based on small numbers, the method of handling 10 year cohorts lending additional uncertainty. Thus, for 10 year olds born in 1904, prevalence is estimated from the 1900-1909 cohort in 1914, who being aged 5-14 will not have had homogeneous smoking habits. Swartz ${ }^{7}$ used $S^{\prime}=21$ or 18 , but we usually used $S^{\prime}=15$, higher values masking the different patterns of starting smoking by cohort, and reducing the occurrence of long term smoking.

Ten year cohorts based on at least 20 subjects were included, the earliest being 1900-1909 for both sexes in AHIP and men in HALS, and 1890-1899 for women in HALS.

\section{Changes in rates}

In tables 5-8, percentage changes in rates are presented for 1955-1970 and 1970-1985, or the nearest periods with predictions available. In figures $1-4$, rates are shown annually over the 30 year period, relative to $1970=100 \%$. In the text a percentage change $\left(P_{1}\right)$ is said to be greater than another $\left(\mathrm{P}_{2}\right)$, if $\mathrm{P}_{1}>\mathrm{P}_{2}$. Thus, a $20 \%$ increase is said to be greater than any increase $<20 \%$ or any decrease, while a $20 \%$ decrease is greater than any decrease $>20 \%$.

\section{Results}

COMPARISON OF OBSERVED AND PREDICTED TRENDS USING THE AGGREGATE METHOD

Table 5 compares percentage changes in LC rates observed in Britain and EW with predictions using the aggregate method, HALS prevalence estimates, standard multistage parameter values, and the "Swartz" submodel with $S^{\prime}=15$. Predicted changes are shown for different estimated "dose" from cigarettes, with varying allowances for cigarettes/smoker, tar/ cigarette and ETS. Figure 1 shows fuller details for men aged 45-54 of observed EW rates and some predicted rates. Patterns in observed rates are similar whether or not Scotland is included, so only EW rates are used subsequently.

For men, observed rates fell throughout virtually the whole period for ages 35-44 and 45-54. For age 55-64, a slight rise to 1960 preceded a plateau, then a fall. With no allowance for variation in cigarettes/smoker or tar/cigarette, predicted changes considerably exceeded observed changes in both time periods and all age groups (that is, predicted rates fell less than observed rates). When the rise in cigarettes/smoker was allowed for, the discrepancy between observed and predicted trends increased, more using the simpler GB estimates of cigarettes/smoker than using the 


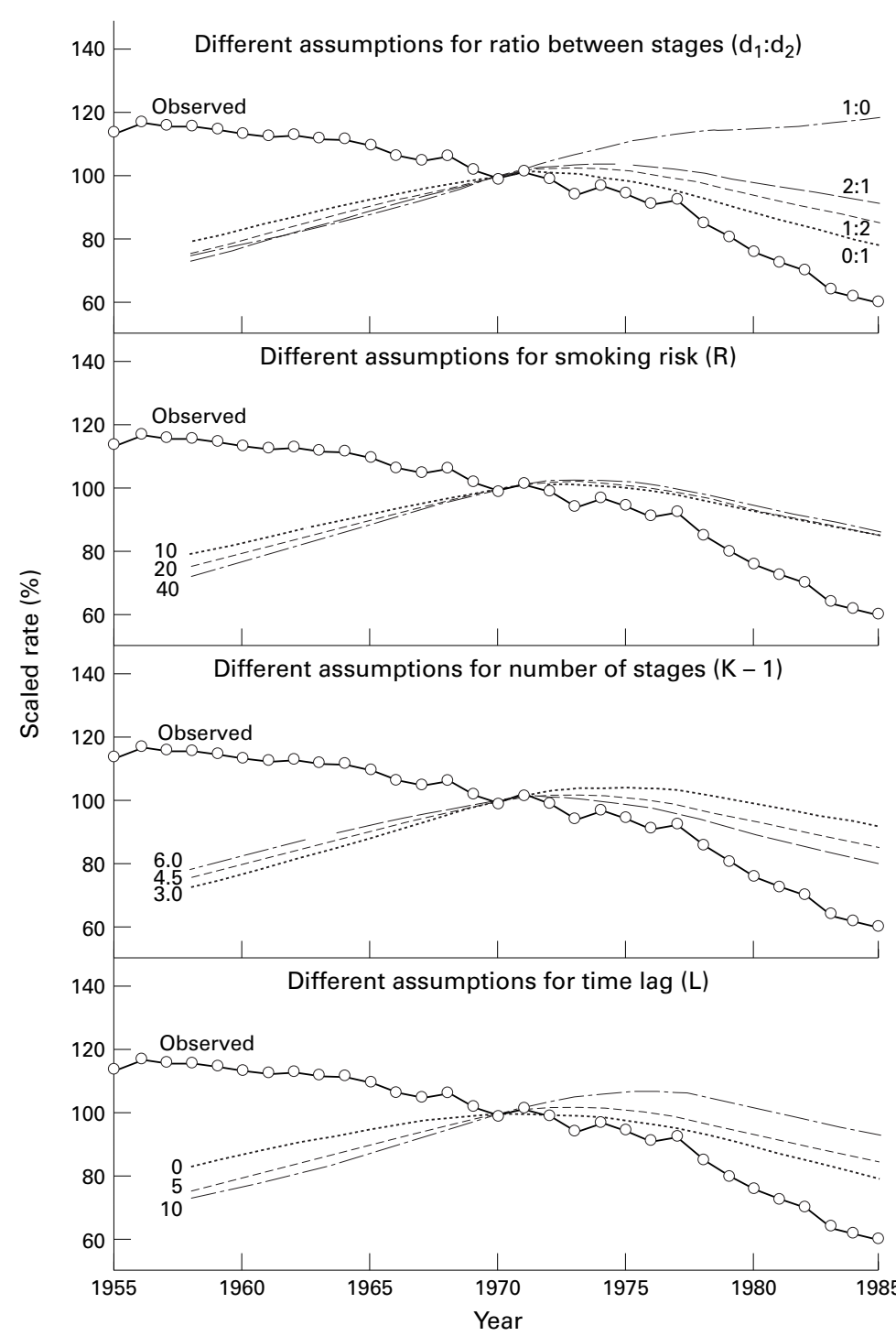

Figure 2 Comparison of observed lung cancer trends in EW for men aged 45-54 and those predicted from the HALS study using the aggregate method and differing multistage model parameters. All predictions use the Swartz smoking submodel with $S^{\prime}=15, G B(2)$ estimates of cigarettes per smoker, TMA estimates of tar per cigarette with square root correction and no dose from ETS. The standard multistage model uses $d_{1}: d_{2}=1: 2, R=20$, $K-1=4.5, L=5$. Other models shown vary one parameter at a time.

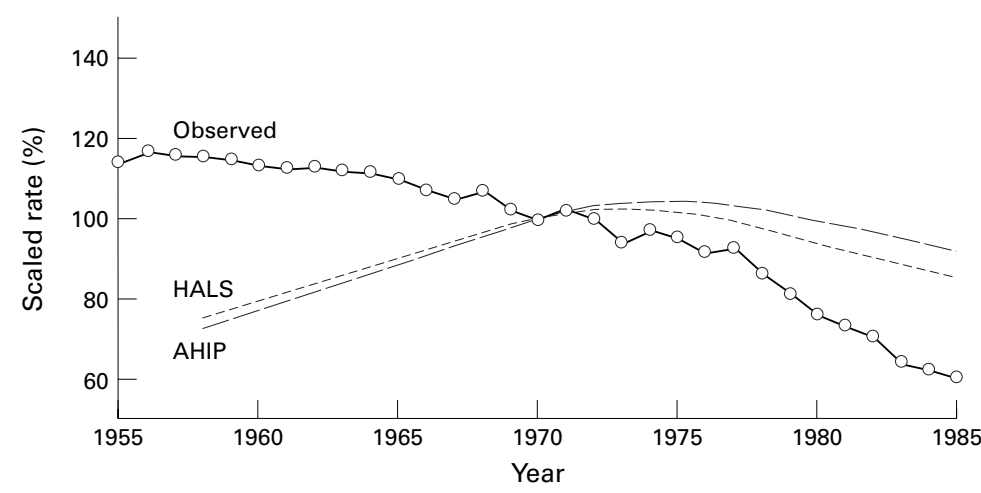

Figure 3 Comparison of observed lung cancer trends in EW for men aged 45-54 and those predicted using the aggregate method from the HALS or AHIP studies. All predictions use $G B(2)$ estimates of cigarettes per smoker, TMA estimates of tar per cigarette with square root correction and no dose from ETS, the standard multistage model $\left(d_{1}: d_{2}=1: 2\right.$, $R=20, K-1=4.5, L=5)$, and the Swartz smoking submodel with $S^{\prime}=15$. cohort specific AHIP estimates. Differences between predictions based on $\mathrm{GB}(1)$ and $\mathrm{GB}(2)$ were small, particularly at younger ages. Predicted risk increased less in the later period when declining tar/cigarette was allowed for, reducing the discrepancy. The discrepancy was little affected by using Wald rather than TMA tar data. When ETS was allowed for, predicted risk increased with increasing $\mathrm{F}$, but only minimally for the lower, more plausible, value. Using a "standard" reasonable set of assumptions, data and multistage parameters:

(i) $\mathrm{GB}(2)$ cigarettes/smoker data,

(ii) square root tar correction, using TMA data,

(iii) no ETS correction,

(iv) $\mathrm{d}_{1}: \mathrm{d}_{2}=1: 2, \mathrm{R}=20, \mathrm{~L}=5$ and $\mathrm{K}-1=4.5$, and

(v) the "Swartz" submodel, with $S$ ' $=15$

the discrepancy between observed and predicted rates in men equates to an annual change in risk unexplained by smoking of $-2.4 \%$ for age $35-44$ (1955-85), $-2.8 \%$ for age $45-54$ (1958-85), and $-1.9 \%$ for age 55-64 (1968-85). Even using full tar correction and AHIP cohort specific cigarettes/ smoker estimates, the "dose" assumptions bringing predicted and observed changes closest, the discrepancies equated to annual changes of $-1.6 \%,-1.4 \%$, and $-0.5 \%$ for the three ages.

For women, rates in the two younger age groups peaked, at around 1970 and 1980 respectively, then declined. In the oldest age group rates rose steadily. For the two younger age groups, predicted and observed changes over the earlier period were similar, but in the later period predicted changes were greater. In the oldest age group observed changes were generally lower than predicted changes. Effects of differing dose assumptions on predictions were similar to those for men, except varying cigarettes/smoker or ETS little affected predictions in the earlier period. The discrepancy between observed and predicted rates was smaller for women than men, equivalent annually, with the "standard" assumptions, to $-1.7 \%$ for age $35-44(1955-85),-0.8 \%$ for age $45-54$ (1955-85) and $+0.8 \%$ for age $55-64$ (1958-85), or with full tar correction and AHIP cohort specific cigarette/smoker estimates to $-0.3 \%,+0.2 \%$, and $+1.8 \%$ respectively.

Table 6 shows the effects of varying the multistage parameters $\mathrm{d}_{1}: \mathrm{d}_{2}, \mathrm{R}, \mathrm{L}$ and $\mathrm{K}-1$ and the smoking submodel, using the aggregate method, HALS smoking prevalence estimates, $\mathrm{GB}(2)$ estimates of cigarettes/smoker and TMA tar estimates with square root correction. Figure 2 shows some predicted rates for men aged 45-54. Increasing $\mathrm{d}_{1}: \mathrm{d}_{2}$, decreasing $\mathrm{K}$ or increasing $\mathrm{L}$ predicted higher changes for men and for the later period for women, but similar or lower changes for women in the earlier period. Increasing $\mathrm{R}$ nearly always predicted higher changes. Varying the smoking submodel had little effect. Increasing S' predicted lower changes. However, effects of differing assumptions were generally small compared with the difference between observed rates and those predicted by the standard model, and, except 
Table 7 Fifteen year percentage changes (by sex, age, and period) in the lung cancer rate observed and in that predicted from the AHIP study using the aggregate method, and differing assumptions

\begin{tabular}{|c|c|c|c|c|c|c|c|c|c|c|c|c|c|c|}
\hline & & & \multicolumn{6}{|l|}{ Men } & \multicolumn{6}{|l|}{ Women } \\
\hline & & & \multicolumn{2}{|l|}{$35-44$} & \multicolumn{2}{|l|}{$45-54$} & \multicolumn{2}{|l|}{$55-64$} & \multicolumn{2}{|l|}{$35-44$} & \multicolumn{2}{|l|}{$45-54$} & \multicolumn{2}{|l|}{$55-64$} \\
\hline & & & $\begin{array}{l}1955- \\
1970\end{array}$ & $\begin{array}{l}1970- \\
1979^{\star}\end{array}$ & $\begin{array}{l}1958- \\
1970^{\star}\end{array}$ & $\begin{array}{l}1970- \\
1985\end{array}$ & $\begin{array}{l}1955- \\
1970\end{array}$ & $\begin{array}{l}1970- \\
1985\end{array}$ & $\begin{array}{l}1955- \\
1970\end{array}$ & $\begin{array}{l}1970- \\
1979^{\star}\end{array}$ & $\begin{array}{l}1955- \\
1970\end{array}$ & $\begin{array}{l}1970- \\
1985\end{array}$ & $\begin{array}{l}1955- \\
1970\end{array}$ & $\begin{array}{l}1970- \\
1985\end{array}$ \\
\hline \multicolumn{3}{|l|}{ Country } & \multicolumn{12}{|c|}{ Observed changes (\%) } \\
\hline \multicolumn{3}{|c|}{ England and Wales } & -22.4 & -33.5 & -13.8 & -39.1 & 13.4 & -23.0 & 35.1 & -20.9 & 68.9 & -12.7 & 87.3 & 64.2 \\
\hline \multicolumn{15}{|l|}{ Dose assumptions } \\
\hline Cig per smoker & $\begin{array}{l}\text { Tar per } \\
\text { cigarette }\end{array}$ & $\begin{array}{l}\text { Model } \\
\text { assumptions }\end{array}$ & \multicolumn{6}{|c|}{ Predicted changes $(\%) \dagger$} & & & & & & \\
\hline Constant & Constant & Standard & 4.5 & -7.7 & 8.1 & -12.6 & & -0.2 & 28.4 & -3.2 & 59.2 & -2.9 & & 45.5 \\
\hline $\mathrm{GB}(2)$ & Constant & Standard & 43.2 & 2.3 & 38.1 & 9.1 & & 25.8 & 57.2 & 15.6 & 70.0 & 30.9 & & 74.7 \\
\hline $\mathrm{GB}(2)$ & TMA-sqrt & Standard & 43.2 & -7.7 & 38.1 & -7.7 & & 8.9 & 57.2 & 5.2 & 70.0 & 11.9 & & 51.8 \\
\hline $\mathrm{GB}(2)$ & TMA-full & Standard & 43.2 & -16.0 & 38.1 & -20.6 & & -4.1 & 57.2 & -3.4 & 70.0 & -2.7 & & 34.2 \\
\hline AHIP & Constant & Standard & 19.6 & -0.9 & 21.8 & -1.4 & & 16.9 & 33.8 & 10.4 & 61.0 & 16.6 & & 55.7 \\
\hline AHIP & TMA-sqrt & Standard & 19.6 & -11.1 & 21.8 & -17.1 & & 0.9 & 33.8 & 0.2 & 61.0 & -0.6 & & 35.6 \\
\hline AHIP & TMA-full & Standard & 19.6 & -19.4 & 21.8 & -29.2 & & -11.4 & 33.8 & -8.3 & 61.0 & -13.7 & & 20.2 \\
\hline $\mathrm{GB}(2)$ & TMA-sqrt & $\mathrm{d}_{1}: \mathrm{d}_{2}=2: 1$ & 45.8 & -3.5 & 44.5 & -0.5 & & 19.1 & 49.9 & 7.5 & 62.3 & 18.4 & & 59.0 \\
\hline $\mathrm{GB}(2)$ & TMA-sqrt & $\mathrm{R}=40$ & 51.1 & -6.8 & 46.4 & -5.8 & & 13.4 & 73.3 & 7.3 & 91.9 & 17.1 & & 68.0 \\
\hline $\mathrm{GB}(2)$ & TMA-sqrt & $K-1=6$ & 38.9 & -12.4 & 32.5 & -14.1 & & 0.2 & 57.6 & 1.2 & 69.8 & 6.5 & & 44.3 \\
\hline $\mathrm{GB}(2)$ & TMA-sqrt & $\mathrm{L}=0 \Omega$ & 29.1 & -11.6 & 25.5 & & & & 50.3 & 0.2 & 63.4 & & & \\
\hline
\end{tabular}

* Change less than 15 years. † Predicted changes for age 55-64 before 1970 not presented as only two year period available. $\ddagger$ Constant at 20 cigarettes per smoker. $§$ Predictions not available after 1980 . All predictions use the Swartz smoking submodel with $S^{\prime}=15$, no dose ETS, and, except as shown, a multistage model with $\mathrm{d}_{1}: \mathrm{d}_{2}=1: 2, \mathrm{R}=20, \mathrm{~K}-1=4.5, \mathrm{~L}=5$.

for some models for the oldest women, the discrepancies remained.

In table 6 , only one parameter was varied at once. Further analyses (not shown) used different combinations of parameter values and dose estimates. Effects of varying parameters were generally similar to those described above, and discrepancies between observed and predicted trends remained.

Our main predictions based on aggregated data, presented in table 5, used prevalence estimates from HALS because of its greater age range and representativeness. Some equivalent analyses, based on AHIP are shown in table 7 while figure 3 compares results with those previously discussed. Results based on AHIP and HALS were generally similar, unsurprisingly because their prevalence estimates agree well (submitted data). For men, predictions rose slightly more and peaked slightly later using AHIP, increasing the discrepancy. For women, the difference was generally the opposite and much smaller.

COMPARING PREDICTIONS USING THE AGGREGATE AND INDIVIDUAL METHODS

Table 8 compares predictions from the two methods using standard multistage parameter values. For the aggregate method, the "Swartz" submodel with $S^{\prime}=15$ was used, either with constant cigarettes/smoker and constant tar/ cigarette, or $\mathrm{GB}(2)$ cigarettes/smoker, TMA tar/cigarette and square root correction. Individual method estimates were based on (a) constant cigarettes/smoker (using only the ages of starting and stopping) and constant tar/ cigarette, (b) the person's varying cigarettes/ smoker history but TMA SWAT values for all cigarettes (with square root correction), or (c) the person's history of both cigarettes/smoker and tar/cigarette (again with square root correction). Estimates for (b) and (c) were available only from AHIP. Figure 4 shows selected results for variable cigarettes/smoker.

Except for women aged 55-64, the individual method generally predicted lower changes than the aggregate method. Allowing tar/cigarette to vary individually also predicted lower changes than if the same value was assumed for all smokers, but only slightly. In the earlier period (not studied for age 55-64), using the individual method little affected the discrepancy between observed and predicted trends. However, for the later period, predictions using the individual method were closer to observed trends. If the last few years of predictions (known to be less reliable) are ignored, this is also true for women age 55-64, where the discrepancy predicted by the aggregate method had been in the opposite direction.

However, the discrepancy remained for men, and women aged 35-44. For instance, using individual cigarettes/smoker and tar/cigarette with square root correction, the discrepancy over the whole period was equivalent to an annual change in risk unexplained by smoking for men of $-2.6 \%$ for age 35-44 (1955-1979), $-1.8 \%$ for age $45-54(1958-85)$, and $-1.6 \%$ for age 55-64 (1968-85) and for women of $-0.9 \%$ for age $35-44$ (1955-79), $-0.5 \%$ for age $45-54(1958-84)$, and $+0.2 \%$ for age 55-64 (1968-85).

Further analyses (not shown) were run using the individual method, comparable to those for the aggregate method in table 6 and figure 2 . The direction of the effect on predicted changes of varying $d_{1}: d_{2}, R, K-1$ or $L$ was similar using both methods in both sexes. The additional analyses confirmed the patterns of discrepancy reported above using the aggregate data and using the individual data with standard multistage parameters.

Further analyses (not shown) demonstrated that limited data on current/latest cigarettes/ 
Table 8 Fifteen year percentage changes in observed lung cancer rate and in predicted risk estimates using the aggregate or individual method

$$
\text { A HALS study }
$$

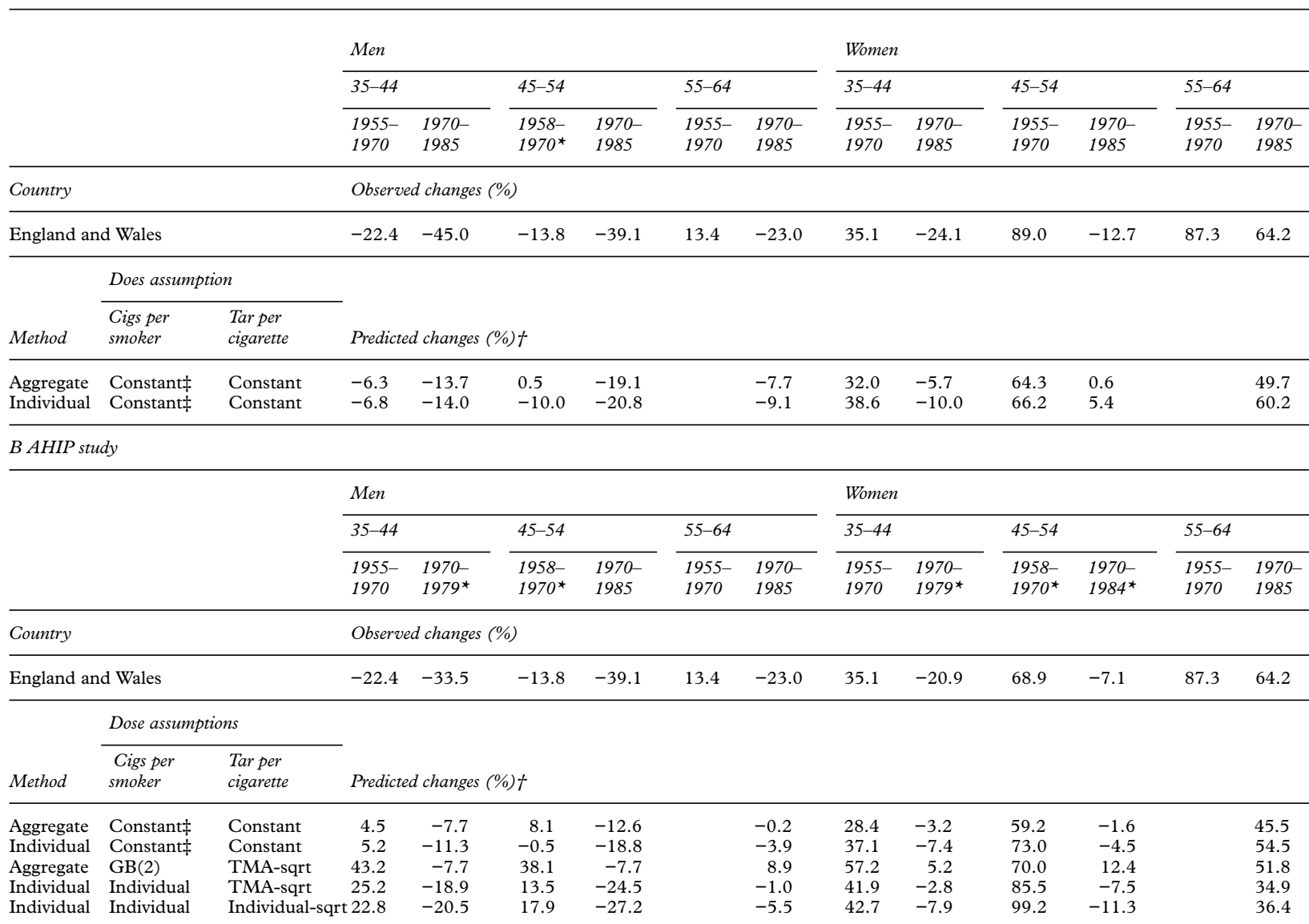

* Change less than 15 years - where predictions are available for different periods for the different methods, the maximum period available for both is shown. $\dagger$ Predicted changes for age 55-64 before 1970 not presented as only six year period or less available. $¥$ Constant at 20 cigarettes per smoker. All predictions use multistage model with $\mathrm{d}_{1}: \mathrm{d}_{2}=1: 2, \mathrm{R}=20, \mathrm{~K}-1=4.5, \mathrm{~L}=5$. Aggregate method uses Swartz smoking submodel with $\mathrm{S}^{\prime}=15$.

smoker, as available in HALS, could not usefully contribute to the individual method.

OTHER TOBACCO PRODUCTS

The analyses so far only consider cigarette smoking. Based on limited data from HALS and AHIP on prevalence of pipe and cigar smoking and from $\mathrm{TMA}^{42}$ on trends in consumption/smoker, we attempted (results not shown) to assess the effect of allowing for pipe and cigar smoking on risk predictions in men. Not surprisingly, because, for many years, cigarettes formed the substantial proportion by weight of total tobacco sales, ${ }^{37}$ such allowance negligibly affected predicted trends.

\section{Discussion}

Using a multistage model and cigarette smoking data we predicted LC trends by sex and age for 1955-1985 and ages 35-64. Smoking histories were obtained from questionnaires. All models reflected changes in smoking prevalence, using either aggregated estimates by 10 year birth cohort, or a person's data on age of starting and stopping. Variation in "dose" from cigarettes was allowed for in various ways, variation in cigarettes/smoker substantially affecting predictions over the whole period, with variation in tar/cigarette affecting predicted trends in later years. However, data sources (whether of prevalence, cigarettes/smoker or tar/cigarette) and allowance for ETS had relatively little effect, as did varying the multistage parameters, provided reasonably plausible values were considered. Using individual smoking histories instead of aggregated data had a reasonably small impact.

For men, models allowing for variation in cigarettes/smoker and tar/cigarette (corrected to allow for "compensation") predicted changes exceeding observed changes throughout the period studied. Basing predictions on individual smoking histories rather than aggregated data reduced this discrepancy in later years, but still represented an annual unexplained change of -1 to $-2 \%$. Even with, implausibly, no allowance for "compensation", the discrepancy remained clearly evident.

For women, nearly all model variants predicted trends similar to those observed for 1955-1970. For ages 35-44 and 45-54, models allowing for variation in cigarettes/smoker and tar/cigarette (with a square root correction), predicted changes exceeding observed changes for 1970-1985. As for men, this discrepancy was reduced using individual smoking histories. Although remaining clear for age 35-44, it was virtually eliminated for age $45-54$. For age 55-64, however, predicted changes in 19701985 were generally lower than observed 

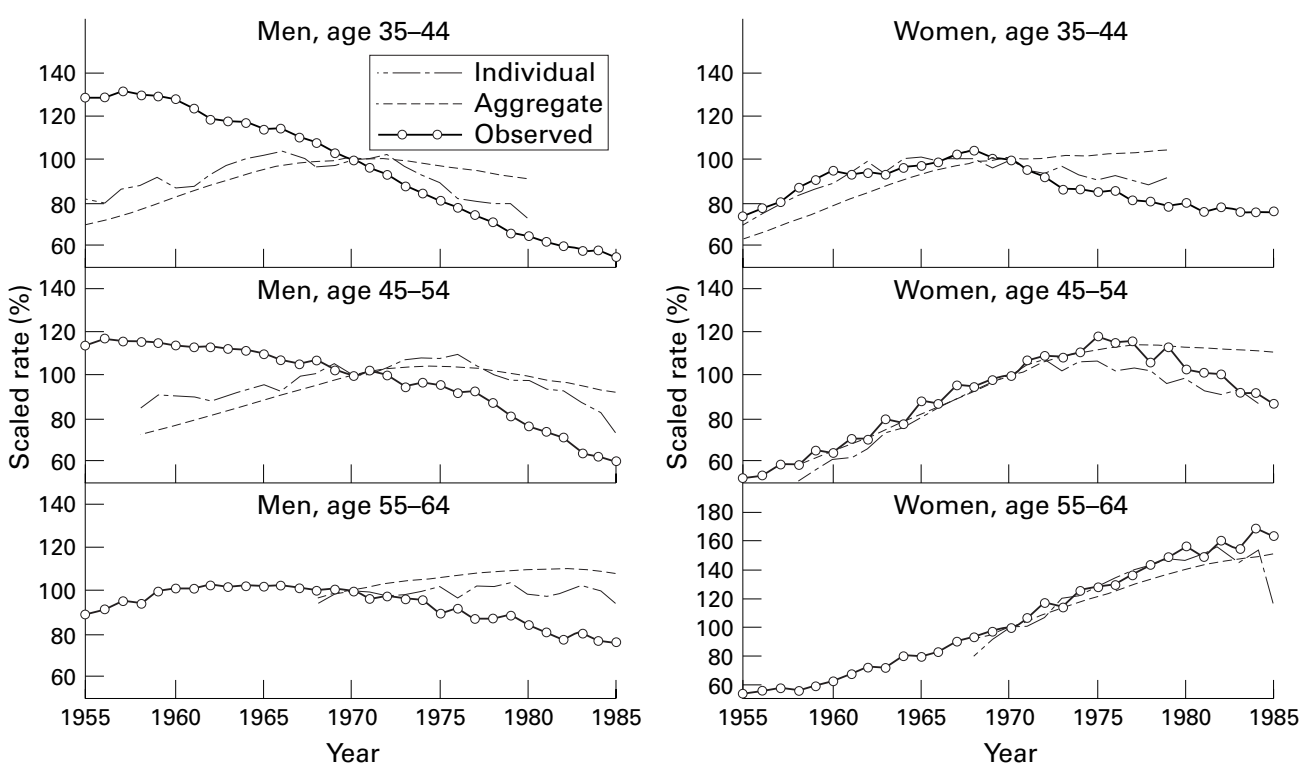

Figure 4 Comparison of observed lung cancer trends in EW, by sex and age, and those predicted from the AHIP study using the aggregate or individual methods. All predictions use multistage model with $d_{t}: d_{2}=1: 2, R=20, K-1=4.5, L=5$. Aggregate method uses Swartz smoking submodel with $S^{\prime}=15, G B(2)$ estimates of cigarettes per smoker, TMA estimates of tar per cigarette and square root correction. Individual method uses individual cigarettes per smoker and tar per cigarette, and square root correction.

changes (depending on the multistage parameters chosen), but this discrepancy too was virtually eliminated using individual histories.

Possible sources of bias include the following:

Changes in diagnostic standards

Although diagnosis of LC is inaccurate, we follow others in assuming detection rates are materially unchanged since $1955 .^{12}$

\section{Inadequacy of recalled smoking data}

Although recalled data are doubtless imperfect, reliance on retrospective data should not have led to spurious time trends in predicted LC rates (submitted data). Any effect of differential smoker/non-smoker mortality in estimating past smoking prevalence is probably minor up to age 70 at interview (submitted data). Discrepancies between observed and predicted changes are larger for age 35-44 (who, for predictions in 1955, were aged approximately 60-69 in AHIP or 65-74 in HALS) than for other age groups suggesting they cannot be explained by differential mortality.

\section{Changes in tar delivery}

We present predictions assuming "dose" to a smoker is (a) independent of tar, (b) directly proportional to tar or (c) proportional to the square root of tar. As substantial epidemiological evidence shows tar reduction is associated with less LC risk, ${ }^{43}$ (a) is implausible, though evidence $^{3940}$ that smokers "compensate" to some extent for reduced yield implies predictions from (b) are probably also incorrect; (c) may predict better. In the analyses using individual smoking histories, we only had data on variation in tar over the past 10 years. As this only minimally affected predictions, lack of earlier data probably had no serious effect. While conceivable that the carcinogenic poten- tial of tar per mg might have changed over time, no reliable evidence supports this conjecture.

Other tobacco products

Our analyses suggest pipe or cigar smoking cannot explain the pronounced discrepancy between observed and cigarette consumption predicted LC trends.

\section{Smoking by children}

With the aggregate method, smoking before $S$ ' is ignored. Although the value $S^{\prime}=21$ Swartz $^{7}$ used seems unnecessarily high, the small difference between predictions using $S^{\prime}=12$ or $S^{\prime}=15$ suggests using $S^{\prime}=15$ in our main analyses did not lead to material error.

With the individual method, age of starting to smoke is fully accounted for. However amounts assumed to be smoked by child smokers (20/day in the constant dose analyses, or amount smoked at age 16 in the variable dose analyses) may have been overestimates. This may partly explain why predictions using the individual and aggregate methods differed more for younger ages, where childhood exposure contributes more.

\section{ETS exposure}

Without individual data, ETS exposure was assumed equal for everyone, irrespective of active smoking status but variable over time proportional to national cigarette consumption. While not unreasonable to assume the dose from a cigarette smoked passively is constant over time, because tar reduction has predominantly affected mainstream not sidestream smoke levels, ${ }^{44}$ exposure may have been affected by changing ventilation of buildings and social patterns. Nevertheless, the modest effect on predictions of allowing for a clearly implausibly high ETS effect $(\mathrm{F}=0.2)$ strongly suggests incomplete allowance for ETS could not have affected our general conclusions. 
Use of inappropriate predictors of $L C$ risk

The multistage model can only approximate the truth. Nevertheless its predictions align with much evidence ${ }^{15}$ and it is flexible, allowing for differing assumptions concerning relative importance of early and late exposure. As conclusions were similar from multistage predictions using a variety of parameters and from predictions based on various simpler predictors not entailing multistage assumptions (results not shown), our conclusions cannot be an artefact of our model. More crucial to predictions is not the decision to use the multistage model but the decision to use parameter values making smoking throughout life relevant to risk. Although, in men, the discrepancy would have been eliminated, or even reversed, had one assumed smoking affects very predominantly the early stage of the process, this is inconsistent with epidemiological data for ex-smokers. ${ }^{15}$ Mathematical modelling ${ }^{32}$ suggests the effect is, if anything, stronger on the later than the earlier stage, implying use of an inappropriate predictor cannot explain our findings.

Considering all these points we conclude cigarette consumption trends cannot fully explain trends in British LC rates, and that the discrepancies observed cannot be attributed to changes in ETS exposure or smoking pipes or cigars.

Our conclusions align with an age-periodcohort analysis, ${ }^{45}$ using mortality data for 1941-85, and estimates of cumulative constant tar cigarette consumption (CCTCC). That analysis showed similarity, in both sexes, between the timing of cohort peaks for CCTCC and for mortality from LC, emphysema, and chronic obstructive lung disease (COLD), but also noted "downward trends in the younger age groups are too large and too early to be explained in terms of changes in the frequency or type of cigarettes smoked."

Our findings also apparently align with analyses $^{47}$ of male LC mortality for 1941-75 based on a simple model allowing for variation in CCTCC. Although " $88 \%$ of total male deaths during the study period could be attributed to smoking," the fitted model notably involved a pronounced decline in risk in non-smokers between 1951 and 1971. Except for analyses incorporating ETS effects, which were generally unimportant, our modelling assumes LC risk in non-smokers is invariant over time. This assumption is consistent with the similarity of age adjusted LC rates in male never smoking British doctors in 1951-71 and $1971-91,{ }^{48}$ but leads to being unable to fit the LC trend data adequately in terms of cigarette consumption.

Further evidence of discrepancies for the USA is presented elsewhere (submitted data), strengthening our major conclusion that factors other than cigarette smoking contribute importantly to overall LC risk.

Our secondary objective was to assess the value using aggregated data, in the form of age and sex specific smoking prevalence estimates at different times, as compared with using individual smoking histories. With non-linear models, using individual data is theoretically
KEY POINTS

- It is often held that time trends in British lung cancer rates merely reflect earlier trends in cigarette smoking habits.

- We tested this belief by using detailed cigarette smoking history data to predict lung cancer trends for 1955-1985.

- Although our modelling took all major aspects of cigarette smoking into account, it could not fully explain the trends.

- We found lung cancer rates declined considerably faster than explicable by cigarette smoking, particularly in younger men.

- We conclude that factors other than cigarette smoking contribute substantially to lung cancer trends and should be investigated more fully.

superior, but often only aggregated data are available. Our analyses suggest using aggregated data leads to quite similar conclusions to those based on individual data, suggesting aggregated data may be useful where individual data are unavailable.

We thank the Health and Lifestyle Survey at the University of Cambridge and the ESRC Data Archive for permission to use the HALS data, WHO for providing the mortality and population data, and Mrs P Wassell for her patient typing.

Funding: financial support was provided by Philip Morris Europe. We alone bear the responsibility for the analysis and interpretation of these data.

Conflicts of interest: none.

1 Peto R, Lopez AD, Boreham J, Thun M, Heath C Jr. Mortality from smoking in developed countries 1950-2000. Indirect estimates from national vital statistics. Oxford: Oxford University Press, 1994.

2 Katzenstein AW. Environmental tobacco smoke and lung cancer risk: epidemiology in relation to confounding cancer risk: epidemiology in relatic

3 Lee PN. Environmental tobacco smoke and mortality. Basle: Karger, 1992.

4 Cox BD, Blaxter M, Buckle ALJ, et al. The health and lifestyle survey preliminary report. London: The Health Promotion Research Trust, 1987.

5 Alderson MR, Lee PN, Wang R. Risks of lung cancer, chronic bronchitis, ischaemic heart disease and stroke in relation to type of cigarette smoked. F Epidemiol Community Health 1985;39:286-93.

6 Armitage P, Doll R. The age distribution of cancer and a multi-stage theory of carcinogenesis. Br F Cancer 1954;8:112.

7 Swartz JB. Use of a multistage model to predict time trends in smoking induced lung cancer. $\mathcal{F}$ Epidemiol Community Health 1992;46:311-15.

8 Townsend JL. Smoking and lung cancer. A cohort data study of men and women in England and Wales 1935-70.f $R$ Stat Soc (Ser A) 1978;141:95-107.

9 Forastière F, Perucci CA, Arca M, Axelson O. Indirect estiForastiere F, Perucci CA, Arca M, Axelson O. Indirect esti-
mates of lung cancer death rates in Italy not attributable to mates of lung cancer death rates in Italy not at
active smoking. Epidemiology 1993;4:502-10.

10 World Health Organization. World Health Statistics Annual. Geneva: World Health Organization, 1955 et seq.

11 Lee PN. Comparison of autopsy, clinical and death certificate diagnosis with particular reference to lung cancer. A review of the published data. APMIS 1994;102 (suppl 45).

12 Royal College of Physicians. Smoking or health. London: Pitman Medical, 1977.

13 Fisher JC, Holloman JH. A hypothesis for the origin of cancer foci. Cancer 1951;4:916-18.

14 Nordling CO. A new theory on the cancer-inducing mechanism. Br f Cancer 1953;1:68-72.

15 Lee PN. Studying the relationship of smoking to lung cancer using the multistage model of carcinogenesis. A review. 1995: Available on request from P N Lee Statistics and Computing Ltd, 17 Cedar Road, Sutton, Surrey SM2 5DA, UK.

16 Doll R. The age distribution of cancer; implications for Doll R. The age distribution of cancer; implications for
models of carcinogenesis. f R Stat Soc (Ser A) 1971;134: models $133-55$.

17 Peto R, Roe FJC, Lee PN, Levy L, Clack J. Cancer and aging in mice and men. Br f Cancer 1975;32:411-26. 
18 Lijinsky W. Life-span and cancer: the induction time of tumours in diverse animal species treated with nitrosoditumours in diverse animal species treated

19 Peto R, Parish SE, Gray RG. There is no such thing as ageing, and cancer is not related to it. Lyon: IARC Scientific Publications No 58, 1985: 43-53.

20 Berenblum I. Sequential aspects of chemical carcinogenesis. In: Becker FF ed. Cancer. A comprehensive treatise. New York: Plenum Press, 1982:451-84.

21 Peto J. Early and late-stage carcinogenesis in mouse skin and man. In: Börzsönyi M, Lapis K, Day NE, Yamaski H, eds. Models, mechanisms and etiology of tumour promotion. Lyon: IARC Scientific Publications 1984:56:359-71.

$22 \mathrm{Kahn} \mathrm{H}$. The Dorn study of smoking and mortality among US veterans: report on $81 / 2$ years of observation. In: Haenszel W, ed. Epidemiological approaches to the study of cancer and other chronic diseases. Bethesda: Natl Cancer Inst Monogr, 1966;19:1-126.

23 Halpern MT, Gillespie BW, Warner KW. Patterns of absolute risk of lung cancer mortality in former smokers. $\mathcal{F}$ Natl Cancer Inst 1993;85:457-64.

24 Doll R, Peto R. Cigarette smoking and bronchial carcinoma: dose and time relationships among regular smokers and lifelong non-smokers. F Epidemiol Community Health 1978;

25 Lee PN, O'Neill JA. The effect both of time and dose applied on tumour incidence rates in benzopyrene skin painting experiments. Br f Cancer 1971;25:759-70.

26 Selikoff IJ, Hammond EC. Multiple risk factors in environmental cancer. In: Fraumeni JF Jr, ed. Persons at high risk of cancer: An approach to cancer etiology and control. New York: Academic Press, 1975: 467-83.

27 Freedman DA, Navidi W. Ex-smokers and the multistage model for lung cancer. Epidemiology 1990;1:21-9.

28 Gaffney M, Altshuler B. Examination of the role of cigarette smoke in lung carcinogenesis using multistage models. $\mathscr{f}$ Natl Cancer Inst 1988;80:925-31.

29 Lubin JH, Blot WJ, Berrino F, et al. Modifying risk of developing lung cancer by changing habits of cigarette smoking. oping lung cancer by chan

30 Brown CC, Chu KC. Use of multistage models to infer stage affected by carcinogenic exposure: example of lung cancer and cigarette smoking. F Chronic Dis 1987;40 (suppl 2):171-9.

31 Brown CC, Chu KC. A new method for the analysis of cohort studies: implication of the multistage theory of carcinogenesis applied to occupational arsenic exposure. Environ Health Perspec 1983;50:293-308.

32 Day NE, Brown CC. Multistage models and primary prevention of cancer. F Natl Cancer Inst 1980;64:977-89.
33 Lee PN. Final analysis - Experiment 1.1.1.9. The effect of stopping painting. London: Tobacco Research Council docuping painting. Lon

34 Whittemore AS. Effect of cigarette smoking in epidemiological studies of lung cancer. Stat Med 1988;7:223-38.

35 Harris JE. Patterns of cigarette smoking. In: US Surgeon General, eds. The health consequences of smoking for women. Washington DC: US DHEW, 1980: 15-42.

36 Rønneberg A, Lund KE, Hafstad A. Lifetime smoking habits among Norwegian men and women born between 1890 and 1974. Int f Epidemiol 1994;23:267-76.

37 Wald N, Nicolaides-Bouman A. UK Smoking Statistics. Second edition. Oxford: Oxford University Press, 1991.

38 Rowland WD, Stevenson MR, Whittaker MW, Wilkes EB. Technical comment on "trends in tar, nicotine, and carbon monoxide yields of UK cigarettes manufactured since 1934," London: Tobacco Advisory Council document TC 989, 1981.

39 Stephen A, Frost C, Thompson S, Wald N. Estimating the extent of compensatory smoking. In: Wald N, Froggatt P eds. Nicotine, smoking and the low tar programme. Oxford: eds. Nicotine, smoking and the low tar prog

40 Adlkofer F, Scherer G, Biber A, et al. Consistency of nicotine intake in smokers of cigarettes with varying nicotine yields. In: Wald N, Froggatt P eds. Nicotine, smoking and the low tar programme. Oxford: Oxford University Press, 1989:116-30.

41 Scherer G, v Maltzan C, v Meyerinck L, Westphal K, Adlkofer F. Biomonitoring after controlled exposure to environmental tobacco smoke (ETS). Exp Pathol 1989;37: $158-63$

42 Lee PN, ed. Statistics of smoking in the United Kingdom. Tobacco Research Council Research Paper I, 7th edition. London: Tobacco Research Council, 1976.

43 Wynder EL, Kabat GC. The effect of low-yield cigarette smoking on lung cancer risk. Cancer 1988;62:1223-30.

44 Independent Scientific Committee on Smoking and Health, Fourth Report. London: HMSO, 1988.

45 Lee PN, Fry JS, Forey BA. Trends in lung cancer, chronic obstructive lung disease, and emphysema death rates for obstructive lung disease, and emphysema death rates for cigarette smoking. Thorax 1990;45:657-65.

46 Osmond C, Gardner MJ. Age, period and cohort models applied to cancer mortality rates. Stat Med 1982;1:245-59.

47 Stevens RG, Moolgavkar SH. A cohort analysis of lung cancer and smoking in British males. Am $\mathcal{f}$ Epidemiol 1984;119:624-41.

48 Doll R, Peto R, Wheatley K, Gray R, Sutherland I. Mortality in relation to smoking: 40 years' observations on male British doctors. BM7 1994;309:901-11. 